\title{
TEACHING SOCIAL ENTREPRENEURSHIP THROUGH PROBLEM-BASED LEARNING: PEDAGOGY AND PRACTICE IN THE BUSINESS ENGLISH CLASSROOM
}

Victoria Tuzlukova, Peter Heckadon

\author{
Sultan Qaboos University, Oman
}

E-mail: victoria@squ.edu.om

\begin{abstract}
This paper introduces the social entrepreneurship project currently incorporated in English for Business course offered by the Centre for Preparatory Studies at Sultan Qaboos University, Oman, in which students identify real world ill-structured problems and acquire knowledge by working together in groups to develop, fund (both through grants/donations and through selling goods and services) and implement solutions to social, cultural, or environmental issues. In more detail, in addition to discussing the concept of social entrepreneurship and its application in student project work and English learning practice, it also explores the effectiveness of a problem based learning approach that relies on the constructive learning principle when teaching social entrepreneurship. Practical recommendations on anchoring social entrepreneurship teaching in problembased learning and constructing social entrepreneurship projects are also considered.
\end{abstract}

Key words: social entrepreneurship, Business English classroom, problem-based learning, Sultan Qaboos University, Oman

\section{INTRODUCTION}

The main objective of English for Specific Purposes (ESP) has always been to "prepare students to use English in scholarly, professional, or working environments" (Basturkmen, 2006, p.17). However, ESP has also appeared to be at the cutting edge of research related to discovering more effective ways and methods for teaching, learning and determining student and community needs (Tarnopolsky \&Vysselko, 2014).

The Sultanate of Oman is currently undergoing substantial economic changes as its government recognizes that its economy must diversify away from reliance on oil revenues. Over the past several decades, non-renewable oil revenues have funded key projects in infrastructure, education, healthcare and other national sectors. This has benefitted the country greatly and allowed the opportunity for more Omani youth to access postsecondary education; however, past over-reliance on oil revenues has led to a situation in which there are not enough meaningful career opportunities for recent graduates. Attempting to absorb these graduates into the public sector economy is not a viable longterm solution (Magd \& McCoy, 2014). Accordingly, the country's government is increasingly looking to economic diversification through the growth of the private sector as a means of addressing the shortage of meaningful work and the issue of job creation.

Submitted February $25^{\text {th }}, 2020$, accepted for publication March $27^{\text {th }}, 2020$ 
Going forward, the government of Oman has laid out policy directives in the field of education as it realizes that future prosperity will be found in a knowledge-based, diversified economy. Here, let us take the Oman 2040 Moving Forward with Confidence policy document (2020), by way of illustration. This document has specified in the educational sector that future "graduates are acquainted with competitive qualifications and employability skills to enter the local and international labor market" (p. 21). Focusing on the need to nurture entrepreneurial potential, talent and creativity of young Omanis, it also states the ideal of "maximizing national capabilities through a national system" (ibid.). Aside from educational objectives, this theme is again stressed in the vision for a more diversified economic structure in which entrepreneurial activities are actively promoted (Oman 2040 Vision, 2020).

Entrepreneurship is not limited to for-profit activities, and in recent years governments around the world have recognized the value of fostering social entrepreneurship. Whereas traditional commercial entrepreneurship encompasses the creation of new for-profit businesses by passionate individuals, social entrepreneurship has as its focus the creation of profit which can then be used to further the greater social good. Roberts and Woods (2005) speak of social entrepreneurship as an opportunity for transformative social change. For the social entrepreneur, the profits that are generated through business activities are re-invested in the venture itself rather than being passed on to shareholders (Harding, 2004). Betts, Laud and Kretinin (2018) provide a workable definition of social entrepreneurship, while defining it as "using profit making enterprises to address social, environmental and other problems that were traditionally entrusted to governmental and non-profit organizations" ( $p$. 32). Although the concept of social entrepreneurship is not widely known in Oman, business owners are starting to speak out. According to a jointly-organized gathering of Omani and British entrepreneurs, there is huge potential for social entrepreneurship in Oman's future (Prins, 2016, n.p.). As well, due to the increasingly difficult economic situation and the lack of sufficient job opportunities for Omani youth, there is a growing interest among young people for the idea of starting their own business according to the founder of Youth Vision, an organization that fosters youth empowerment (ibid.). Two organizations in Oman that are concerned with economic development, The Public Authority for Small and Medium Enterprises Development (Riyada) and Knowledge Oman, recently established an initiative to promote social entrepreneurship (Riyada, 2016). These initiatives clearly demonstrate that social enterprises not only contribute to the betterment of society, but also aid in job creation and social inclusion. Consequently, more effective preparedness of youth for changing business, social and professional practices is an urgent need in the Sultanate of Oman, and the country is eager to be at the forefront in training young Omani entrepreneurs who are able to meet the needs of the present without compromising the ability of future generations to meet theirs, pursue new applications and be extremely passionate about their work. As a result, there have been adaptations and changes in the country's educational policies, community initiatives, classroom methodologies, teaching methods and instructional approaches to support students' learning and their development as individuals who are able to pursue innovative ideas with the potential to benefit the community. These were added by curriculum developments to help students get engaged in activities that suggest societal and individual obligations and enthusiasm, and start to develop as social entrepreneurs who can recognize social problems, achieve social change by employing entrepreneurial principles, processes and operations, and demonstrate ethical and sensitive behavior at earlier stages of their careers, and it could not be agreed more that the ESP curriculum is no exception in such endeavors. 


\section{TEACHING SOCIAL ENTREPRENEURSHIP THROUGH PROBLEM-BASED LEARNING}

\section{Problem-Based learning model}

University graduates today require more than simply the possession of knowledge in a field of discipline. Wingspread (1994, cited in Duch, Groh \& Allen, 2001) elucidates the following core competencies that are required to be successful in the working world: (1) high level skills in communication, (2) technological literacy and competence, (3) the ability to make informed judgments based on the evaluation of information, (4) the ability to function in team settings, and (5) the ability to devise solutions for complex, illdefined, real-world problems. Problem-Based Learning (PBL) is an educational approach that aims to develop and hone these crucial skills. The essence of PBL involves the use of complex, real-world problems in which students work together in teams to acquire, communicate and integrate information, and thereby in that process, come up with workable solutions. PBL addresses many of the learning outcomes that are widely used in post-secondary education, for example, the ability to think critically and analyze problems, the ability to find and evaluate information, the ability to work in a team setting and communicate effectively with that team, and the development of intellectual skills to become lifelong learners (Duch, Groh \& Allen, 2001).

For PBL to be at its most effective as an instructional tool, problems utilized in the setting of a university course should satisfy the following criteria (Duch, 2001). The problem should engage students and motivate them to devise a solution. Real-world problems are deemed more useful than superficial ones as students will more likely perceive themselves to be possible stakeholders. Problems should require students to seek out practical information, and decide what information is useful and what is superfluous. Students should also be encouraged to question their own assumptions since complex real-world problems do not have prescribed solutions. Ideally, the problem is complicated enough so that students must work in groups to effectively find solutions. Cooperative learning is fostered when students synthesize information from a variety of sources and build a knowledge framework together based on principles that they are exposed to in the course. The problem must be open-ended enough so that it does not resemble "end of chapter" questions that could be easily divided up among the group members. Finally, the problem task should be structured so that it challenges students to engage in higher order thinking skills, moving them into Bloom's (1956, cited in Duch, 2001) cognitive skills of analyzing, synthesizing and evaluating.

\section{Social entrepreneurship competencies}

It has been argued that social entrepreneurs deal with similar issues that commercial entrepreneurs deal with, namely in the areas of mobilizing resources, recognizing opportunities and building organizations (Tracey \& Philips, 2007, cited in Pache \& Chowdhury, 2012). Successful resolution of these issues necessitates the possession of a range of competencies by the social entrepreneur. Miller, Wesley and Williams (2012) identified a number of needed competencies through a survey of 150 social entrepreneurship practitioners, including top managers, founders and funders of social enterprises. Among the identified competencies were the following: (1) ability to challenge traditional ways of thinking, (2) interpersonal communication skills, (3) innovativeness and creativity (4) ability to communicate with stakeholders, (5) management of financial 
capital, (6) ability to lead and develop others, (7) capacity to measure outcomes, (8) manage strategy development, (9) ability to problem solve, and (10) ability to develop collaborative relationships (Miller, Wesley \& Williams, 2012). Upon further examination, the majority of these competencies fall under the groupings of critical thinking skills that are not subjectspecific but rather, transferable (Halpern, 1998, cited in Butterworth \& Thwaites, 2013), communicative and collaborative skills, creative thinking skills and analytical skills. The Problem-Based Learning framework, when thoughtfully devised, can lend itself to the fostering of these skill areas.

\section{Constructivist learning and PBL}

The theory that student learning takes place when they are actively engaged in the construction of mental representations has long been advocated by such thinkers as Vygotsky, Dewey and Piaget (Hunter, 2015; Olusegun, 2015). Constructivist learning theory espouses an approach in which students actively engage in their own learning and knowledge construction (Fernando \& Marikar, 2017). Sjoberg (2007, cited in Fernando \& Marikar, 2017) sees learning as knowledge that is actively constructed by the learners themselves, making it more than simply the transmission of knowledge. Since learning is not imposed, but is actively constructed by the learner, participatory learning is essential. Problem identification, the sourcing of information and problem solving require learning to be an active experience on the part of the learner, resulting in experiential learning. Cunningham, Duffy and Knuth (1993, cited in Hunter, 2015) have identified the characteristics of a constructivist learning environment. Key aspects include: (1) knowledge construction must be experiential; (2) information must be actively sought, organized, analyzed, and interpreted; (3) learning must be embedded in realistic contexts involving social experience; (4) learner self-awareness must be encouraged; and (5) learners must be given the chance to express their voice, giving them agency. The operationalization of a constructivist learning environment advocates group collaboration in the solving of problems (Hunter, 2015). As well, constructivist learning calls for the instructor to play the role of facilitator; aiding students to become active learners in their own learning, through the meaningful connection of prior knowledge with new knowledge as they construct their own mental representations of the world around them, is characteristic of the constructivist learning classroom (Olusegun, 2015). Problem- Based Learning, as a teaching and learning approach, has been recognized by many theorists and practitioners as one of the ways in which a constructivist learning environment can be utilized (Hunter, 2015). Such a learning environment as elucidated in research by Lobler (2006) "supports and explains a lot of the requested changes in the entrepreneurial education” (p.19).

\section{PBL and higher order thinking skills}

Critical thinking is seen as an indispensable skill in the field of higher education (Kek \& Huijser, 2011). Precise definitions are elusive, but critical thinking is generally described as the ability to use higher order thinking skills, such as the analysis, synthesis and evaluation of information, particularly in the area of problem solving. Paul and Elder (2006, cited in Kek \& Huijser, 2011) see critical thinking as self-directed, self-monitored, self-disciplined and self-corrective. Bloom's taxonomy of learning (Anderson \& Krathwohl, 2001, cited in Blundell \& Berardi 2016) denotes learning according to a hierarchy of lower and higher order processes. Remembering and understanding are 
mental processes that belong to lower levels, whereas analyzing, evaluating, and creating are categorized as higher-order learning processes. Accordingly, in order for critical thinking to take place in tertiary education classrooms, students must move beyond the lower level processes of remembering and understanding, and engage in analytical, evaluative and creative tasks.

In practical terms, the inclusion and operationalization of critical thinking as a skill into tertiary education curricula has not been without its challenges. Theorists have argued for some time that real critical thinking must go beyond the typical "end of chapter" questions found in many college and university textbooks. According to a study carried out by Marshall and Carson (2008) that examined the end of chapter questions in eight leading textbooks in business schools, almost $90 \%$ of the questions did not go beyond Levels 1 and 2 (Knowledge and Comprehension) on Bloom's (1956, cited in Marshall \& Carson, 2008) Taxonomy Scale. This is a situation in which "correct" answers to questions are immediately available within the chapter itself. Students are rarely challenged by textbook questions to go beyond the chapter, or indeed beyond the course material (Marshall \& Carson, 2008). To move students' thinking processes beyond the lower levels of Bloom's Taxonomy is an area of concern among theorists and practitioners, especially in an era of increasing automation and digitization of traditionally knowledge-based career fields. $21^{\text {st }}$ century employers want graduates who can think critically and solve problems (Alshare, 2018; Tuzlukova \& Singh, 2018).

Problem-Based Learning has been advocated as an approach to fostering and developing students' critical thinking skills (Kek \& Huijser, 2011; Kurniawati, 2019; Marshall \& Carson, 2008). It has been found useful in creating an environment in which higher order thinking skills are nurtured and stimulated (Raiyn \& Tilchin, 2015). The literature is rich in the advantages that are conferred on student learning when a PBL approach is adopted. Among the abilities that have a chance to flourish are (Nilson, 2016): critical thinking and analysis, conceptual understanding and deep learning, application of metacognitive strategies, decision making and problem solving. To exemplify, Albanese and Dast (2014, cited in Vandenhouten, Groessl, \& Levintova, 2017) compiled two decades' worth of PBL research and found that students in the health sciences exhibited enhanced retention of knowledge, increased confidence in finding solutions to problems and greater comfort when working in teams.

In the future, the nurturing of critical thinking in educational environments will not only be desirable from the standpoint of promoting critical thinking, it will become an economic necessity. According to the World Economic Forum Annual Meeting in 2018, by the year 2030, robots could replace 800 million jobs (n.p.). Relying solely on a "knowledge-based approach" to education would be shortchanging future graduates who increasingly will not be able to compete with automation. Rather, education needs to focus more on a skills-based model, where teamwork and independent, critical and creative thinking is encouraged and developed (World Economic Forum, 2018).

\section{ANALYSIS OF CURRENT PRACTICE: SOCIAL ENTREPRENEURSHIP COMPONENT OF ENGLISH FOR BUSINESS COURSE AT SULTAN QABOOS UNIVERSITY}

The English for Business III course is a compulsory course for all students registered in the College of Economics and Political Science at Sultan Qaboos University. It is part 
of the degree plan for the following majors: accounting, information systems, economics, finance, management, marketing, operations management and business statistics.

The vast majority of students are Omani nationals; classes occasionally have an international student. There is an equal mix of male and female students. Most of the students are in their third year of university study, with the average age being 20 years old. They come from all parts of Oman - both urban and rural. Average English proficiency would likely be in the IELTS 5.0 to 6.0 range, with the occasional student being a band 7.0 or above. Students are admitted to the course only after the successful completion of the English for Business II course. In their third year of study, at the same time they are taking the English for Business III course, students take common business and economics courses. In their fourth year, in their respective degree plans, students choose their business specializations.

The English for Business III course is divided into three components: academic reading skills, academic writing skills and Problem-Based Learning. The reading and writing skills component utilizes business case studies to supply content that is meaningful and relevant both in the context of Oman and overseas. Both global and local business and economic issues are discussed. Through the course of class discussions, reading and writing tasks, and visual media clips, students have the opportunity to identify, analyze and evaluate a range of issues that for-profit and non-profit organizations face in the world today while enhancing their competency in business language skills.

The case studies make use of such business themes as strategy formulation and implementation, vision and mission statements, marketing in the context of different industries and locales, as well as cross-cultural advertising, human resources, corporate culture and social media branding and communication. It is in the Problem-Based Learning component of the course where social entrepreneurship is the focus. In studentled teams of three or four members, students begin by identifying humanitarian issues of importance to them. These issues along with social problems, also focus on environmental problems and their solutions to bring a positive change in society. They then begin the process of information collection, analysis and evaluation to determine an optimal way in which their social enterprise could operate in the alleviation of social ills brought about by the impact of such causes as poverty, natural or manmade disasters, discrimination, ineffective state policy or societal ignorance.

After having performed PEST and SWOT analysis, students then formulate a proposal for a non-profit organization, through the crafting of vision and mission statements, the design of their organizational structure, a proposed budget - taking revenue generation and expenses into account, the creation of a website and the design of an overall organizational strategy that focuses on sustainability, both in the environmental and financial sense.

Student interaction with digital platforms is a key component of teaching and learning in the English for Business course. Course materials are available for students to access on a Moodle course page. The course Moodle website includes such components as course learning outcomes, a course outline, suggested timelines for the completion of the stages of the project, a discussion forum, academic vocabulary quizzes, links to webbased resources to assist in the design of their non-profit organization proposal, videos that illustrate course content, assessment rubrics, and reflection assignments related to the process and outcomes of group work. Students find the Moodle discussion forum useful, as it provides an opportunity every week to interact with the instructor and each other on issues related to common business themes, such as the elements of corporate strategy, 
how to formulate and write vision and mission statements, business terminology and academic vocabulary, and other issues of importance. As for language input, students develop and expand their vocabulary and enhance their business-related knowledge and skills. To illustrate, students share their ideas and opinions about the key course business concepts and report on their self-perceived acquisition of these concepts. This also appears, according to studies by Pace (1990) and Rovai and Barnum (2003), to be a valid measure of learning as students' decisions about learning are often based on their perceptions (Rovai \& Barnum, 2003). For example, for one assignment students create a post on Moodle discussion forum in response to the questions on what they know about social entrepreneurship, how it is differentiated from 'regular' or commercial entrepreneurship, and practical aspects of entrepreneurial development in Oman including reasons and possible perspectives. The questions are meant to probe student impressions of social entrepreneurship's likely future and impact on Oman. For students to successfully respond to the questions, they first watch some suggested videos posted on Moodle to explain the key factors concerning the rise of social entrepreneurship as a phenomenon, and how it differs from commercial entrepreneurship. As elucidated by Tracey and Phillips (2007), the videos explain the three unique challenges faced by social entrepreneurs, namely, the management of accountability, the double bottom line and the management of identity. Whereas commercial enterprises are accountable to their owners and shareholders, social entrepreneurs aim to be accountable to the beneficiaries of their social mission. The only way they can build legitimacy is through having a positive relationship with their non-profit stakeholders. The double bottom line refers to the necessity of having both social and commercial interests maintain financial viability. Non-profit financing may come through personal, commercial and governmental donations. Additionally, many social enterprises engage in for-profit commercial activities to fund their social mission. Finally, there is the issue of managing identity since there is often an overlap between the for-profit and non-profit dimensions of the social enterprise. Tension may result due to these dual identities, however "regardless of their commitment to their social vision, only by operating profitably can social entrepreneurs engender sustainable social change" (Tracey \& Phillips, 2007, p. 267).

English for Business students' understanding of social entrepreneurship, according to their posts on Moodle discussion forum, relates to "finding new solutions for social problems by creating businesses, social engagement and social services," "developing, funding and implementing" such solutions and, consequently, "achieving a benefit to society and serving its members before achieving the financial benefit." Though the ideas of social engagement, social services and community benefit are present in students' responses, when asked about the reasons behind an individual choice to be a social entrepreneur, they describe them in relation to both community and their personal lives. For example, one of the students reported that "social entrepreneurship is not just about business but also a lifestyle." Another student, in the same vein, noted that social entrepreneurship "makes me able to find that support quicker to help people." The related ideas are clearly seen in students' posts that explain the reasons for considering social entrepreneurship as an opportunity "for providing immense benefit for the society and its residents," individual choice of a citizen who wants to "help change the environment and find solutions to everyday problems," and "have a good impact on people's lives, meet humanity interest goals, and have people to support each other as one," and action that has positive effects "on society and can change people's lifestyle to the better." In their posts, students are mostly optimistic about the perspectives of social entrepreneurship 
growth in Oman in the future and its possible benefits to Omani society. They relate the concept of social entrepreneurship to the individual attributes that can make them able to gain and maintain employment. To quote one student, "social entrepreneurship will grow in Oman in the future: it will benefit the society by creating job opportunities and increasing employability, and help develop health awareness and education." Similarly, another student responds that "the community needs this service as it contributes to the reduction in unemployment." Students recognize the existing potential of social entrepreneurship in Oman as "a response to community needs", that include, for example, a "need to reduce many problems, whether in the economic, educational or health sectors." According to students' views, social entrepreneurship "will be very beneficial for a lot of people in need when it comes to their education and finances, and also the environment; we will prosper in a more positive way." It is noteworthy to mention that besides social issues related to social entrepreneurship, as well as social value creation through entrepreneurial activities (Leadbeater, 2006), when explaining the concept, students also make connections of social entrepreneurship with the Omani culture and cultural values and traditions. To illustrate, according to one student, "social entrepreneurship has high opportunities to grow in Oman in the future because of our traditional values not to mention that we are a kind nature society that may have already took supportive actions toward each other but in different ways. Furthermore, managing these kinds of businesses will reduce unemployment rates and raise awareness as well as skills about the environmental problems." Such perspective of viewing social responsibility through cultural dimensions is emphasized, for example, in a study by Volero, Siano, Palazzo and Amabile (2019) who have examined how organizations are influenced by cultural dimensions in communicating their social responsibility efforts.

\section{IMPLICATIONS FOR SOCIAL ENTREPRENEURSHIP TEACHING IN OMAN}

Incorporating social entrepreneurship through Problem-Based Learning in the tertiary business English classroom fulfills several functions. First, it is more closely aligned to the ' $21^{\text {st }}$ century skills' paradigm of teaching and learning. As our world becomes increasingly borderless and globalized, people from different cultures and contexts will have more opportunity to interact. This requires tertiary education to be more than the simple transmission of factual information; it requires higher order thinking skills so that citizens have the tools to identify, evaluate and create knowledge as it is needed so that they function successfully in the workplace and beyond (Teo, 2019). Stated another way, students must learn how to learn not just what to learn. Due to the ubiquitous nature of smart phones and internet connections, locating factual information has never been easier. Indeed, the mere possession of publicly available information is unlikely to confer any unique workplace advantage to the average person. According to Internet Live Stats (2020), on a typical day there are now over 4.4 billion internet users and 3.6 billion Google searches. In the year 2020, according to World Economic Forum website post, the internet hosts 44 zettabytes of information, which is equivalent to 44 trillion gigabytes (How much data, 2020). Information paucity is not the main issue. Rather, it is the evaluation, synthesis and application of information that is the essential skill since this results in the creation of new knowledge. Stated more plainly, it is not the information that one possesses that matters, but what is done with that information. The Partnership for $21^{\text {st }}$ Century Skills (2006, cited in Teo, 2019) elucidates three broad skill areas needed for citizens to function 
effectively: critical and inventive thinking, information and communication adeptness, and civic literacy and global awareness. The social entrepreneurship project contains elements of all these three broad skill areas.

Second, the teaching and learning of social entrepreneurship is interdisciplinary in nature. There is also a built-in interdisciplinary nature in Problem Based Learning approach (Shirokikh et al., 2017) that positively impacts students' language learning and development of their higher order thinking skills. This not only hones higher order thinking skills; it also provides opportunities to engage in the type of complex problem solving skills that are valued in the workplace. Ivanitskaya, Clark, Montgomery, and Primeau (2002) argue that interdisciplinary learning gives students greater skills at dealing with complex fields of knowledge that are lacking in structure. Further, interdisciplinary education compels students to find connections among seemingly unrelated domains. This higher order thinking process results in a personalized process in constructing and organizing knowledge (Ivanitskaya, Clark, Montgomery, \& Primeau, 2002). Lim, Wyatt, Mariotz, and Browning-Samoni (2012) contend that going through the experience of interdisciplinary learning results in improved thinking skills that are transferable across academic and professional domains. Thus, graduates with these skills are more likely to thrive in the globalized workplace.

Finally, the teaching and learning of social entrepreneurship holds long term benefits for the Sultanate of Oman. Social entrepreneurs as described by Howaldt, Domanski and Schwarz (2015) are "actors which invent, develop and achieve a new frame of reference of entrepreneurial action and thereby a new social practice in the society (p.96). Therefore, entrepreneurs can be key drivers of employment in $21^{\text {st }}$ century economies (Bakheet, 2018). As well, there appears to be keen interest among Omani university students to learn about and listen to success stories regarding entrepreneurship. According to a study by Belwal, $\mathrm{Al}$ Balushi and Belwal (2015) conducted at Sohar University, the majority of students not only expressed interest in one day starting a business, but also felt that the university classroom was the proper place in which to learn about entrepreneurship. The students also stated that they wanted to see university courses enhance the level of, and opportunities for, learning about starting up a business. In addition to providing job opportunities, social entrepreneurs can also play a vital role in overcoming social problems in society at large. In the area of providing assistance to disabled people for example, social entrepreneurship has been playing an active role in the past several years (Prins, 2016). By promoting the concept of social entrepreneurship, especially to small and medium enterprises, some societal ills may have a chance to be alleviated.

\section{CONCLUSION}

This paper looked into social entrepreneurship teaching and learning currently integrated in the Business English course offered by the Centre for Preparatory Studies at Sultan Qaboos University in Oman while considering some pedagogical approaches and giving some practical illustrations of these processes. The examination revealed some meaningful perspectives and pedagogical orientations; a Problem-Based Learning approach could stimulate students to view the problem from a different point of view and enable them to look for solutions that are both innovative and creative, thus teaching them how to transfer knowledge in new ways and develop life-long learning skills. Additionally, it can be effectively used to prepare Omani students for the $21^{\text {st }}$ century needs of employment and 
empower them as responsible and accountable citizens in the future by way of the professionally oriented context of learning and academic advancement of ESP.

\section{REFERENCES}

Alshare, K. (2018). A gap analysis of business students' skills in the $21^{\text {st }}$ century case study. Academy of Educational Leadership Journal, 22(1), 1-22. Retrieved February 22, 2020 from https://www.abacademies.org/articles/a-gap-analysis-of-businessstudents-skills-in-the-21st-century-a-case-study-of-qatar-6974.html

Bakheet, A. H. (2018). Relationship between attitudes and intentions for business startup: A case of Omani university and college students. Academy of Entrepreneurship Journal, 24(2), 1-10.

Basturkmen, H. (2006). Ideas and options in English for specific purposes. Mahwah: Lawrence Erlbaum Associates.

Belwal, R., Al Balushi, H., \& Belwal, S. (2015). Students' perception of entrepreneurship and enterprise education in Oman. Education + Training, 57(8/9), 924-947.

Betts, S. C., Laud, R., \& Kretinin, A. (2018). Social entrepreneurship: A contemporary approach to solving social problems. Global Journal of Entrepreneurship, 2(1), 31-40.

Blundell, G., \& Berardi, V. (2016) Developing capable undergraduate students: A focus on problem-based learning and assessment. Information Systems Education Journal, 14(1), 71-85.

Butterworth, J., \& Thwaites, G. (2013). Thinking skills: Critical thinking and problem solving (2nd edit.), Cambridge: Cambridge University Press.

Duch, B. J. (2001). Writing problems for deeper understanding. In B. J. Duch, S. E. Groh, \& D. E. Allen (Eds.) The Power of Problem-based Learning : A Practical "how to" for Teaching Undergraduate Courses in Any Discipline (1st ed., pp. 47-54). Virginia: Stylus Publishing.

Duch, B. J., Groh, S. E., \& Allen, D. E (2001). Why problem based learning? A case study of institutional change in undergraduate education. In B. J. Duch, S. E. Groh, \& D. E. Allen (Eds.), The Power of Problem-based Learning: A Practical "how to" for Teaching Undergraduate Courses in Any Discipline (1st ed., pp. 3-11). Virginia: Stylus Publishing.

Fernando, S., \& Marikar, F. (2017) Constructivist teaching/learning theory and participatory teaching methods. Journal of Curriculum and Teaching, 6(1), 110-122.

Harding, R. (2004). Social enterprise: The new economic engine? Business Strategy Review, 15(4). 39-43.

How much data is generated each day? (2020). Retrieved February 16, 2020, from weforum.org.

Howaldt, J., Domanski, D., \& Schwarz, M. (2015). Rethinking social entrepreneurship: The concept of social entrepreneurship under the perspective of socio-scientific innovation research. Journal of Creativity and Business Innovation, 1, 88-98. Retrieved February 22, 2020, from http://www.journalcbi.com/uploads/3/1/8/7/ 31878681/rethinking_social_entrepreneurship_the_concept_of_social_entrepreneursh ip_under_the_perspective_of_socio-scientific_innovation_research.pdf. 
Hunter, B. (2015). Teaching for engagement: Part 1: Constructivist principles, case-based teaching, and active learning. College Quarterly, 18(2). Retrieved February 20, 2020, from http://collegequarterly.ca/2015-vol18-num02-spring/hunter.html.

Internet live stats (2020). Retrieved February 20, 2020, from http://internetlivestats.com.

Ivanitskaya, L., Clark, D., Montgomery, G., \& Primeau, R. (2002). Interdisciplinary learning: Process and outcomes. Innovative Higher Education, 27(2), 95-111.

Kek, M. Y. C. A., \& Huijser, H. (2011). The power of problem-based learning in developing critical thinking skills: preparing students for tomorrow's digital futures in today's classrooms. Higher Education Research \& Development, 30(3), 329-341.

Kurniawati, T. (2019). Improving students' higher order-thinking skills through problembased learning in Introduction to Microeconomics course. International Conference on Economics, Education, Business and Accounting (3rd ICEEBA), Bali, Indonesia, 25-27 October, 2018, Dubai, UAE: KnE Social Sciences.

Leadbeater, C. (2006). The Socially Entrepreneurial City. In A. Nicholls (Ed.), Social Entrepreneurship: New Models of Sustainable Social Change (233-246). Oxford: Oxford University Press.

Lim, C. M., Wyatt, N., Mariotz, E., \& Browning-Samoni, L. (2012). Integrative thinking for business education: Interdisciplinary learning and assessment. Business Education Innovation Journal, 4(1), 5-13.

Lobler, H. (2006). Learning entrepreneurship from a constructivist perspective. Technology Analysis \& Strategic Management, 18(1), 19-38.

Magd, H. A. E., \& McCoy, M. P. (2014). Entrepreneurship in Oman: Paving the way for a sustainable future. Procedia Economics and Finance, 15, 1632-1640.

Marshall, J. B., \& Carson, C. M. (2008). A preliminary Bloom's Taxonomy assessment of end-of-chapter problems in business school textbooks. American Journal of Business Education, 1(2), 71-77.

Miller, T. L., Wesley, C. L., \& Williams, D. E. (2012). Educating the minds of caring hearts: Comparing the views of practitioners and educators on the importance of social entrepreneurship competencies. Academy of Management Learning \& Education, 11(3), 349-370.

Nilson, L. (2010). Teaching at its best: A research-based resource for college instructors. 3rd ed. San Francisco, CA: Jossey-Bass.

Olusegun, S. (2015) Constructivism learning theory: A paradigm for teaching and learning. IOSR Journal of Research \& Method in Education, 5(6), 66-70.

Oman 2040 Vision. (2020). Policy document of the Sultanate of Oman. Retrieved January 26, 2020, from https://www.2040.om/wp-content/uploads/2020/02/ Oman2040Vision-Document-\%E2\%80\%93-Arabic-FinalENC.pdf.

Pace, C.R. (1990). The undergraduates: A report of their activities and progress in college in the 1980's. Los Angeles, CA: Center for the Study of Evaluation, University of California, Los Angeles.

Pache, A. C., \& Chowdhury, I. (2012). Social entrepreneurs as institutionally embedded entrepreneurs: Toward a new model of social entrepreneurship education. Academy of Management Learning \& Education, 11(3), 494-510.

Prins, E. (2016). Social entrepreneurship has huge potential in Oman. Times of Oman. Retrieved February 20, 2020, from timesofoman.com.

Raiyn, J., \& Tilchin, O. (2015). Higher-order thinking development through adaptive problem-based learning. Journal of Education and Training Studies, 3(4), 93-100. 
Riyada, Knowledge Oman sign agreement to promote social entrepreneurship (2016). Muscat Daily. Retrieved February 19, 2020, from https://archive.muscatdaily.com/ Archive/Oman/Riyada-Knowledge-Oman-sign-agreement-to-promote-socialentrepreneurship-4mx3.

Roberts, D., \& Woods, C. (2005). Changing the world on a shoestring: The concept of social entrepreneurship. University of Auckland Business Review, 7(1), 45-51.

Rovai, A.P., \& Barnum, K.T. (2003). On-Line Course Effectiveness: An Analysis of Student Interactions and Perceptions of Learning. Journal of Distance Education, 18(1), 57-73. Retrieved September, 16，2019， from http://topshare.che.nl/downloadattachment/ 177224/Artikel\%20over\%20eff\%20van\%20online\%20studeren.pdf.

Shirokikh, A. Y., Ganina, E. V., Balandina, L. A., Shvechkova, L. A., Malugina, N. M. (2017). Interdisciplinary Approach to Teaching ESP: Problem-Based Assignment and Students' Feedback. Eurasian Journal of Analytical Chemistry, 12(7b), 1581-1589.

Tarnopolsky, O., \& Vysselko, A. (2014). Mini-courses on economic disciplines in an advanced ESP course for university students on economics. The Journal of Teaching English for Specific and Academic Purposes, 2(1), 45-59.

Teo, P. (2019). Teaching for the 21st century: A case for dialogic pedagogy. Learning, Culture and Social Interaction, 21, 170-178.

Tracey, P., \& Phillips, N. (2007). The distinctive challenge of educating social entrepreneurs: A postscript and rejoinder to the special issue on entrepreneurship education. Academy of Management Learning \& Education, 6(2), 264 -271.

Tuzlukova, V., \& Singh, V. (2018). Twenty first century skills through problem based learning: An ESP perspective. Journal of Teaching English for Specific and Academic Purposes, 6(3), 413-423.

Vandenhouten, C., Groessl, J., \& Levintova, E. (2017). How do you use problem-based learning to improve interdisciplinary thinking? New Directions for Teaching and Learning, 151, 117-133.

Volero, A., Siano, A., Palazzo, M. \& Amabile, S. (2019). Hoftsede's cultural dimensions and corporate social responsibility in online communication: Are they independent constructs? Corporate Social Responsibility and Environmental Management, 27(1), 53-64.

World Economic Forum Annual Meeting (2018). Retrieved February 15, 2020, from https://www.weforum.org/events/world-economic-forum-annual-meeting-2018. 